\title{
POLÍTICAS DE EDUCAÇÃO INFANTIL: DESAFIOS A PARTIR DA CRIANÇA E SUAS ESPECIFICIDADES
}

\author{
POLÍTICAS DE LA PRIMERA INFANCIA: DESAFÍOS DE LOS NIÑOS Y SUS \\ ESPECIFICIDADES
}

\section{EARLY CHILDHOOD POLICIES: CHALLENGES FROM THE CHILD AND ITS SPECIFICITIES}

\author{
Douglas Henrique Rodrigues SILVA ${ }^{1}$ \\ Graziela Cristina de Oliveira $\mathrm{HOLMO}^{2}$ \\ Ione da Silva Cunha NOGUEIRA ${ }^{3}$
}

RESUMO: A educação infantil, primeira etapa da educação básica, tem a finalidade de cuidar e educar de crianças de 0 a 5 anos e adquiriu caráter educativo com as concepções que emergiram da Constituição Federal de 1988. Por outro lado, historicamente a infância é vista como período de fragilidade e dependência, porém, a Sociologia da Infância lança luz a uma nova visão das crianças e das infâncias, percebendo-as como ativas. O presente artigo tem como objetivo analisar a legislação que serve como base para a realização de políticas para a Educação Infantil, buscando perceber os conceitos de criança (s) e infância (as) ali presentes. Partindo dos pressupostos epistemológicos da Sociologia da Infância buscou-se identificar o reconhecimento social da infância e dimensionar os principais atos legais e norteadores da Educação Infantil no Brasil, delimitando os desafios para a realização do trabalho na educação da primeira infância.

PALAVRAS-CHAVE: Políticas públicas. Infância. Sociologia da infância.

RESUMEN: La educación infantil, primera etapa de la educación básica, tiene el propósito de cuidar y educar a los niños de 0 a 5 años y adquirir un carácter educativo con los conceptos que surgieron de la Constitución Federal de 1988. Por otro lado, históricamente la niñez, se ve como un periodo de fragilidad y dependencia, sin embargo, la Sociología de la Infancia refleja luz sobre una nueva visión de los niños y de la infancia, percibiéndolos como activos. Este artículo tiene como objetivo analizar la legislación que sirve de base para la implementación de políticas de Educación Infantil, buscando comprender los conceptos de niño (s) y niñez (as) alli presentes. A partir de los supuestos epistemológicos de la Sociología de la Infancia, se busca identificar el reconocimiento social de la infancia y dimensionar los principales actos jurídicos y rectores de la Educación Infantil en Brasil, delimitando los desafios para el desempeño del trabajo en la educación infantil.

PALABRAS CLAVE: Políticas públicas. Infancia. Sociología infantil.

${ }^{1}$ Universidade Federal do Mato Grosso do Sul (UFMS), Três Lagoas - MS - Brasil. Mestrando em Educação. PPGE. ORCID: https://orcid.org/0000-0003-2061-9508. E-mail: dhenriquersilva@hotmail.com

${ }^{2}$ Secretaria Municipal da Educação de Assis, Assis - SP. Responsável pelo Departamento de Educação Infantil e Pedagógico. Mestre em Educação pela UNESP/Marília. ORCID: https://orcid.org/0000-0001-6070-2846. Email: grazipedagogicoinfantil@gmail.com

${ }^{3}$ Universidade Federal do Mato Grosso do Sul (UFMS), Três Lagoas - MS - Brasil. Professora Associada. PPGE. ORCID: https://orcid.org/0000-0003-4179-2166. E-mail: ionescnogueira@gmail.com

RPGE- Revista on line de Política e Gestão Educacional, Araraquara, v. 25, n. esp. 4, p. 2018-2030, dez. 2021. e-ISSN: 1519-9029 DOI: https://doi.org/10.22633/rpge.v25iesp.4.15937 
ABSTRACT: Early childhood education, the first stage of basic education, has early childhood education from 0 to 5 years and acquired an educational character with the concepts that emerged from the Federal Constitution of 1988. On the other hand, historically childhood is seen as a period of fragility and dependence, however, the Sociology of Childhood sheds light on a new vision of children and childhoods, perceiving them as active. This article aims to analyze the legislation that serves as a basis for implementing policies for early childhood education, seeking to understand the concepts of child(ren) and childhood(as) present there. Based on the epistemological assumptions of the Sociology of Childhood, we sought to identify the social recognition of childhood and to measure the main legal and guiding acts for carrying out Early Childhood Education in Brazil, delimiting the challenges for carrying out work in early childhood education.

KEYWORDS: Public policies. Childhood. Childhood sociology.

\section{Introdução}

Pode-se dizer que o reconhecimento da criança pequena, como merecedora de uma educação de qualidade é recente. Historicamente o surgimento das instituições que atendiam às crianças pequenas, foi marcado pelo viés assistencialista, visando muito mais atender a uma necessidade das mães do que propriamente das crianças.

No Brasil, desde a promulgação da Lei de Diretrizes e Bases da Educação Nacional, a Educação Infantil passou a ser vista como importante momento para o desenvolvimento das crianças de 0 a 6 anos de idade, sendo reconhecida como primeira etapa da Educação Básica. Importante reconhecimento, pois durante muito tempo a educação da criança pequena foi considerada responsabilidade das famílias e o cuidado oferecido pelas instituições existentes se limitava a um atendimento exclusivamente assistencialista, oferecido às famílias pobres como meio de atender suas necessidades de pais e mães trabalhadores.

Tais alterações podem ser compreendidas como resultado da mudança na forma de se enxergar a infância e suas potencialidades. A criança é vista como ser de capacidades e potencialidades. Não como um vi-a-ser, mas como alguém que já é. Que é capaz de aprender e contribuir com seu próprio desenvolvimento muito mais do que se imaginava antes.

Nesse sentido, a Sociologia da Infância aponta para uma concepção de criança que a percebe como parte integrante da sociedade, possuidora de um protagonismo jamais imaginado na Idade Moderna quando se pode dizer que a percepção da criança enquanto alguém que possuía peculiaridades teve seu início. Essa é a concepção de criança que tem sido indicada como o ponto central das preocupações e ações educacionais e escolares. Pensar as instituições de educação da criança pequena a partir dessa concepção significa trazer novas propostas de organização e desenvolvimento das atividades educacionais. Atividades que 
levem em consideração as potencialidades das crianças e suas necessidades básicas para seu efetivo desenvolvimento físico, cognitivo, emocional e social.

O presente artigo tem como objetivo analisar a legislação que serve como base para a realização de políticas para a Educação Infantil, especificamente as Diretrizes Curriculares Nacionais para a Educação Infantil (BRASIL, 2009) e a Base Nacional Comum Curricular (BRASIL, 2017), buscando perceber os conceitos de criança (s) e infância (as) ali presentes e a maneira como essa concepção pode vir a impactar na realização do trabalho pedagógico.

Nesse sentido o texto se divide em três partes. Na primeira é realizada a descrição dos conceitos de infância(s) e criança(s) a partir dos teóricos da Sociologia da Infância, Willian Corsaro (2011) e Jens Qvortrup (2011), na segunda parte é feita análise das Diretrizes Curiculares Nacionais da Educação Infantil (DCNEIs) e da Base Nacional Comum Curricular (BNCC) e na terceira se estabelece a discussão a respeito dos desafios postos à educação infantil a partir das questões apresentadas.

\section{Visões sobre criança e infância sob a perspectiva da Sociologia}

Por influência da Psicologia e da Filosofia, a educação historicamente atribuiu um sentido negativo à infância, sendo considerado período de falta, de fragilidade, dependência e negatividade. Sob esse viés, a criança é considerada não pelo que é, mas sim pelo que poderá se tornar, o "vir-a-ser", e para que tal situação pudesse ser alcançada, sob as perspectivas propostas, a escola seria primordial.

Sob esse ponto de vista, o padrão é o adulto, ele é o modelo a ser seguido pela criança e a educação é o processo que poderá contribuir para o alcance desse objetivo. Ela servirá como meio de civilização ou purificação daquele estado de menoridade. Quanto a esta questão, Kramer (1995, p. 21) demonstra que, sob esse ponto de vista, a criança é considerada como um ser que ainda não é social e que possui um papel secundário nas relações sociais, “tanto em relação à produção dos bens materiais, quanto em relação à participação nas decisões". A autora mostra que o desenvolvimento da criança é percebido como desenvolvimento cultural de suas possibilidades naturais de criança, ao invés de socialmente determinado e condicionado por sua origem social.

Kramer também alerta para o perigo de pensar uma criança universal a partir do conceito de natureza infantil. O problema é que essa visão, baseada na ideia de natureza infantil dissimula o poder exercido pelo adulto sobre a criança de maneira ideológica, pois trata como natural uma "superioridade" que foi estabelecida socialmente. Cria-se e mantém-se 
uma dependência social da criança que "é transformada em dependência natural, sendo justificada pelo adulto de forma absoluta" (KRAMER, 1995, p. 21).

Nesse contexto social, existe um conceito de criança abstrato, de "cunho humanista", que é contraposto a um conceito de criança único, que se pretende como científico, estabelecendo-se uma falsa oposição, que pode ser assim considerada, uma vez que em ambas a criança é encarada como se fosse a-histórica e como se seu papel social e seu desenvolvimento independessem das condições de vida, da classe social e do meio cultural de sua família (KRAMER, 1995).

A partir das concepções da sociologia da Infância, as crianças começam a ser considerada parte integrante da sociedade passando-se a ponderar que não são apenas influenciadas, mas também exercem influência sobre tudo o que as cerca. Sob essa perspectiva, as crianças deixaram de ser vistas como aquelas que devem ser socializadas pela família e pela escola para serem percebidas como seres inseridos na cultura que com ela se relacionam trazendo igualmente suas contribuições.

As crianças não estão limitadas a imitar e internalizar o mundo ao seu redor, mas passam a interpretar, dar sentido e participar da cultura, pois no processo de atribuir sentido ao mundo adulto, começam a produzir coletivamente seus próprios mundos e sua cultura. Corsaro (2011) desenvolve a ideia de culturas de pares que segundo ele, não são fases que cada criança vive, mas elas produzem e participam ativamente dessas culturas sendo as produções incorporadas à sua teia de experiências. Essas experiências vivenciadas não são abandonadas quando amadurecem ou se desenvolvem, mas permanecem como parte de suas histórias como integrantes ativos de sua cultura.

Tal ideia se amplia a partir da concepção do sociólogo norueguês Jens Qvortrup. Esse autor defende a noção de que a infância é uma categoria da estrutura social, estando totalmente integrada à sociedade. Para comprovar essa teoria, o autor apresenta nove teses, dentre as quais, a concepção de que a infância é uma forma particular e distinta em qualquer estrutura da sociedade, que, porém, está “exposta (econômica e institucionalmente) às mesmas forças sociais que os adultos, embora de modo particular" (QVORTRUP, 2011, p. 207).

De acordo com o autor, todos estão expostos aos eventos mais amplos que ocorrem além do "microcosmo" e as crianças por sua vez, terão menos condições de resistir a tais eventos e influências, principalmente pelas condições a que estão submetidas enquanto crianças pela própria rede social a que estão ligadas. Assim, a sociedade as coloca em um papel de subalternidade que por si só dificultaria seu poder de ação. 
O autor mostra que a criança é categorizada como grupo minoritário, assim definido a partir da ideia do grupo dominante, que se apresenta como os adultos, possuidores de status social mais alto e maiores privilégios. É um grupo considerado à parte da sociedade, possuindo um tratamento desigual e diferenciado devido à suas características físicas ou culturais, e acrescentamos que em situações diversas ou convenientes ao grupo adulto, são desconsideradas e até mesmo desrespeitadas. Assim, percebe-se que as crianças são tratadas de maneira desigual e subalterna com a desculpa de sua fragilidade e incapacidade apenas quando isso é conveniente ao universo adulto.

Nesse sentido, o mundo adulto se mostra muito mais propenso a mantê-las alienadas e preparadas para permanecerem em seu estado de "infância", no sentido de falta, dependência e fragilidade do que de lhes oferecer meios para terem suas possibilidades de atuação na sociedade reconhecidas, embora em algumas classes sociais isso tenha que acontecer por razões de necessidade do próprio adulto.

Pensar uma instituição educativa que supere essas questões tão arraigadas na sociedade é um desafio constante, pois implica colocar em xeque a visão de adultos dos próprios educadores e dos pais das crianças atendidas por essa instituição escolar e que muitas vezes se mostram extremamente conservadores e sem disposição para discutir novas visões relacionadas ao protagonismo infantil. Assim, muitas dessas ideias referentes à infância, ainda não se apresentam de maneira plena dentro das instituições e das salas de aula, necessitando de discussão aprofundada. Embora tantos estudos sejam realizados para se pensar pedagogias e metodologias diferenciadas, a instituição e seus atores encontram-se expostos às exigências do sistema, que são impostas a todos, relegando à segundo plano aquela que deveria ser sua prioridade: a criança.

\section{A educação Infantil no Brasil e a legislação}

Em 2009, a Emenda Constitucional $\mathrm{n}^{\mathrm{o}}$ 59, passou a tornar obrigatória e gratuita a Educação Básica de quatro a dezessete anos, ou seja, a Educação Infantil passa a ser obrigatória às crianças de quatro a cinco anos. Essa emenda contribui para a ampliação do acesso e democratização da oferta dessa Etapa de Ensino.

No mesmo ano, foram aprovadas as novas Diretrizes Curriculares Nacionais para a Educação Infantil (BRASIL, 2009) que trouxeram novas concepções para o trabalho a ser realizado na Educação Infantil ao trazerem concepções de infância, criança, currículo, 
proposta pedagógica, desenvolvimento, aprendizagem e a ação docente, que deve ter como eixos curriculares norteadores as interações e a brincadeira, considerando a criança como

Sujeito histórico e de direitos, que, nas interações, relações e práticas cotidianas que vivencia, constrói sua identidade pessoal e coletiva, brinca, imagina, fantasia, deseja, aprende, observa, experimenta, narra, questiona e constrói sentidos sobre a natureza e a sociedade, produzindo cultura (BRASIL, 2009, art. $4^{\circ}$ ).

As Diretrizes rompem com orientações oficiais anteriores, possibilitando uma prática educativa centralizada na criança e nas suas relações. De acordo com Dantas (2016, p. 179), "O documento destaca também, o atendimento à diversidade, às especificidades das crianças pequenas e bebês e a relação com a família".

Diante do exposto, observa-se que as Diretrizes de Curriculares Nacionais para a Educação Infantil (BRASIL, 2009), representaram um grande avanço na qualidade da educação ofertada às crianças. Apesar de todo uma longa história de lutas pelo reconhecimento político e legislativo, as raízes amargas de uma educação voltada para atender as exigências do mercado capitalista, bem como a concepção de uma infância generalizada e abstrata, estava entranhada nos currículos educacionais. E quando se trata de educação, nenhuma mudança acontece num viés imediato, muitos anos são necessários para se vislumbrar qualquer prenuncio de mudança. Dessa forma, a Educação Infantil aconteceu e ainda acontece de diferentes formas, seguindo diferentes caminhos.

Gradativamente, com o desenvolvimento da sociedade, o sistema dos modos de produção laborais, atrelados ao desenvolvimento econômico e a exploração do Capital, ensejam a precarização do trabalho. Nesse sentindo, Antunes (2018, p. 120), assevera que

Assim, em plena era da informatização do trabalho no mundo maquinaldigital, vem ocorrendo também um processo contraditório, marcado pela informalização do trabalho (trabalhadores sem direitos), presente na ampliação dos terceirizados/subcontratados, flexibilizados, trabalhadores em tempo parcial, teletrabalhadores, potencializando exponencialmente o universo do trabalho precarizado.

Nesse novo cenário das condições de trabalho, assim como ao longo de toda a história, a educação é obrigada a se moldar para favorecer a nova demanda do mercado. Com as relações laborais fragmentadas, que tipo de educação é necessário ofertar? Que tipo de indivíduo é necessário formar?

Oito anos após a publicação das Diretrizes Curriculares Nacionais para a Educação Infantil, no dia 22 de dezembro de 2017 foi publicada a Resolução $\mathrm{CNE} / \mathrm{CP} \mathrm{n}^{\circ}$ 2, que institui 
e orienta a implantação da Base Nacional Comum Curricular (BNCC) para a Educação Infantil e Ensino Fundamental.

A BNCC traz em seu texto a definição de ser um documento de caráter normativo que “define o conjunto orgânico e progressivo de aprendizagens essenciais que todos os alunos devem desenvolver ao longo das etapas e modalidades da Educação Básica" (BRASIL, 2017).

No que se refere às aprendizagens essenciais, o documento indica que, durante todo o curso da Educação Básica, essas devem assegurar aos estudantes o desenvolvimento de dez competências gerais, que consubstanciam, no âmbito pedagógico, os direitos de aprendizagem e desenvolvimento. Nesse sentindo o documento defende competências como a "mobilização de conhecimentos (conceitos e procedimentos), habilidades (práticas, cognitivas e socioemocionais), atitudes e valores para resolver demandas complexas da vida cotidiana, do pleno exercício da cidadania e do mundo do trabalho" (BRASIL, 2017).

No contexto da Educação Infantil, o documento traz a mesma definição de criança presente nas Diretrizes Curriculares Nacionais para a Educação Infantil, bem como reafirma as interações e brincadeiras como eixos estruturantes dessa etapa de ensino. Nessa perspectiva, o documento estabelece seis direitos de aprendizagem e desenvolvimento para assegurar as condições efetivas do processo de ensino e aprendizagem, sendo eles: Conviver, Brincar, Participar, Explorar, Expressar-se e Conhecer-se. Assim, pode-se analisar que sugestão da Base é sistematizar a metodologia para que todas as crianças aprendam de forma homogênea, não levando em consideração que a aprendizagem acontece de maneira heterogênea, propõe ainda um trabalho centralizado no desenvolvimento do currículo, deixando de priorizar o desenvolvimento da criança em suas múltiplas potencialidades.

A Base Curricular, assim como os Referenciais Curriculares traz em seu escopo a ideia de uma fragmentação do currículo, estipulando objetivos de aprendizagem e desenvolvimento divididos em cinco campos de experiências. Nesse caminho o documento subdivide esses objetivos de acordo com a faixa etária das crianças sendo, Bebês (zero a um ano e seis meses), Crianças bem pequenas ( 1 ano e 7 meses a 3 anos e 11 meses) e Crianças pequenas ( 4 anos a 5 anos e 11 meses).

Nesse sentindo, a escolarização precoce das crianças ganha força, ao instituir o que e quando se deve aprender. De acordo com Monteiro et. al (2018 p. 207) "a partir dos objetivos definidos no documento, consideramos um silenciamento não só das crianças, mas das/os docentes como potencializadores e criativos".

Considerando a autonomia das instituições públicas e privadas, a Base tem o pressuposto da construção de currículos diversos, de acordo com as características, realidades 
e necessidades dos alunos, desde que tais propostas estejam adequadas às estabelecidas pela própria Base.

Nesse viés, pode-se observar a dicotomia entre a dimensão teórica e prática do documento. Por compor uma política educacional vinculada às avaliações censitárias de escala nacional e sem uma fundamentação epistemológica e teórica, permite que cada instituição, sistema e estado estabeleça seu próprio currículo, no entanto impõe que todas as crianças serão avaliadas a partir dos pressupostos nacionais. As diversidades sociais e culturais são desconsideradas, produzindo uma visão padronizada de criança e aprendizagem baseada em resultados.

Ao se discutir acerca do currículo proposto pela BNCC, Marsiglia (2017, p. 108) et al. anunciam que se por um lado a "classe trabalhadora luta pela democratização do acesso ao conhecimento produzido pelo conjunto da humanidade ao longo de sua história, a burguesia busca secundarizar a escola, esvaziando-a". Ainda segundo as autoras, essa versão foi desprovida de “conteúdos científicos, artísticos e filosóficos, [tendo sido dada] [...] ênfase em métodos, procedimentos, competências e habilidades voltadas para a adaptação do indivíduo aos interesses do grande capital" (MARSIGLIA et al., 2017, p. 109), o que demonstra a força da classe empresarial no processo de elaboração do documento.

Diante do exposto, a reforma educacional trazida pela implantação da Base, acende a um currículo que privilegie o desenvolvimento de habilidades e competências necessárias a inserção em um mercado de trabalho precarizado e fragmentado. A formação integral do indivíduo e o reconhecimento das especificidades das diferentes infâncias que compõe os corredores das instituições educacionais permanecem apenas no discurso.

\section{Os desafios da Educação Infantil}

Conforme exposto anteriormente, as políticas públicas para a infância no Brasil, são marcadas por uma caminhada marcada por muitas lutas, conquistas, impasses e desafios. Kramer (2007, p. 2), destaca que "hoje, vivemos o paradoxo de ter um reconhecimento teórico avançado sobre a infância, enquanto assistimos com horror à incapacidade da nossa geração lidar com as populações infantis e juvenis".

Como educar crianças nesse contexto? Qual o currículo ideal para uma educação significativa na e para a infância? Qual o caminho a seguir? Entre os muros da Educação Infantil, os impasses e desafios da vertente política para a composição de um currículo de qualidade têm muitas vezes tirado a voz das crianças. 
No cotidiano da educação infantil é possível presenciar a realização de atividades descontextualizadas, com enfoque na memorização de letras e números, rotinas que determinavam a hora de estudar, hora de dormir, hora disso, hora daquilo, mas que nunca levavam em conta a opinião e a vontade dos mais interessados: as crianças. A escolarização precoce introduz a ideia de que as crianças precisam se preparar o quanto antes para o Ensino Fundamental, desenvolver habilidades e competências para se tornarem cidadãos bons e adequados a sociedade. No cotidiano institucional, a criança ainda é vista como um ser em devir, moldável que precisa aprender, aprender e aprender.

Nos corredores das escolas e instituições de Educação Infantil, o mundo apresentado às crianças é fragmentado e limitado. Sem experiências, sem partilhas, sem sentimento a infância é registrada nas inúmeras atividades que preenchem os portfólios vistados de ora em vez, pelos pais.

É urgente a necessidade de um trabalho a ser realizado numa "perspectiva de humanização, de resgate da experiência, de conquista da capacidade de ler o mundo, de escrever a história coletiva, nos apropriando das diversas formas de produção de cultura." (KRAMER, 2007 p. 7).

Neste sentido, quando se observa a importância da Educação Infantil, se faz necessário olhar para como esta etapa está organizada, como os professores, educadores e equipe gestora compreendem a infância, quais conceitos trazem, como garantem o direito que as crianças têm à infância de qualidade, pois

o campo da Educação Infantil vive um intenso processo de revisão de concepções sobre educação de crianças em espaços coletivos, e de seleção e fortalecimento de práticas pedagógicas mediadoras de aprendizagens e do desenvolvimento das crianças. Em especial, têm se mostrado prioritárias as discussões sobre como orientar o trabalho junto às crianças de até três anos em creches e como assegurar práticas junto às crianças de quatro e cinco anos que prevejam formas de garantir a continuidade no processo de aprendizagem e desenvolvimento das crianças, sem antecipação de conteúdos que serão trabalhados no Ensino Fundamental (BRASIL, 2009 p. 7).

Neste sentido, Mello (2000 apud BARROS, 2009, p. 44)) nos alerta que:

Se as concepções que temos são essenciais na definição de modo que atuamos, parece que temos aí uma forte razão para refletir sobre como nós educadores, percebemos a criança, como entendemos suas possibilidades e capacidades, a forma de que pensamos que ela aprende. Tais concepções - a concepção de criança, de processo de conhecimento - e a maneira como entendemos a relação desenvolvimento-aprendizagem e a relação aprendizagem-ensino orientam nossa atitude ao organizar a prática 
pedagógica que desenvolvemos. Uma análise do que estamos fazendo verdadeiramente pode começar, então por aí: perguntando-nos que conceito de criança tem orientado nossa prática ou orienta as práticas, de modo geral, e como isso tem determinado as práticas da educação da infância.

Dessa forma, garantir a qualidade da Educação Infantil é compreender que a mesma só acontecerá quando a infância for de fato reconhecida e a criança compreendida como um ator social, capaz e intérprete da cultura. É preciso promover o direito das crianças de serem crianças, de brincarem, sonharem, questionarem, pesquisarem, conhecer e compreender o mundo. É preciso descentralizar e descolonizar o currículo da voz adulta e deixar que as próprias crianças sejam protagonistas.

\section{Considerações Finais}

Partindo de uma concepção abstrata e generalizada de criança, o atendimento as crianças no Brasil, foi guiado pelos moldes Europeus e Norte Americanos, e assim como na história da construção da sociedade brasileira, a perspectiva idearia era bem diferente da realidade. O currículo da educação brasileira foi colonizado aos ideais de uma elite burguesa.

A percepção de criança dentro da sociedade foi evoluindo gradativamente com o desenrolar da história. A concepção de um ser em devir, de adulto em miniatura, invisível ao contexto social pela sua incompletude e imperfeição se modificou dando espaço a uma concepção na qual a criança é vista como um ser social, transformadora e produtora de cultura. No entanto esse reconhecimento muito difundido no plano do discurso político e na descrição dos textos legais. A efetivação desse reconhecimento, foi negligenciada pela falta de recursos, deficiência na formação dos professores, bem como pela costura sistêmica dos pressupostos educacionais enviesados aos interesses mercadológicos do Capital.

Quando a organização laboral da sociedade acontece em um contexto tecnicista, segundo o qual, o indivíduo para exercer uma função, garantir um emprego, deve ter uma formação baseada em técnicas especificas, a educação é formatada ao mesmo viés. De forma fragmentada, o processo de ensino e aprendizagem concentra-se no ensino de conteúdos específicos. Nesse mesmo caminho, quando o mercado precariza e informaliza os modos de produção e de trabalho, a sociedade necessita de cidadãos com habilidades e competências limitadas e delineadas a esse viés, a educação se desenha ao desenvolvimento de apenas dez competências gerais.

A Lei de Diretrizes e Bases da Educação Nacional de 1996, reafirma e valida a conquista da preocupação com a educação assumir o atendimento das crianças de zero a seis 
anos, trazida com a aprovação da Constituição Federal de 1988. Nesse contexto, a criança passa a ser vista como um ser de direitos, o que enseja a criação do Estatuto da Criança e do Adolescente em 1990.

A Educação Infantil passa a acontecer no interior de instituições designadas para tal fim, deixando de oferecer um atendimento meramente assistencialista, para privilegiar uma proposta educativa. No entanto, o Brasil é um país extenso e constituído por uma ampla diversidade social e cultural, dessa forma, a Educação Infantil acontece de diferentes formas e em caminhos diversos pelos municípios brasileiros.

As Diretrizes Curriculares Nacionais para a Educação Infantil (BRASIL, 2009), constituem um grande ganho para a educação da primeira infância, pois configura um atendimento de qualidade para as crianças, percebendo essa etapa de ensino como indispensável para o desenvolvimento infantil e não apenas como uma etapa preparatória para o Ensino Fundamental.

Considerando a criança como sujeito histórico, de direitos e ser social, o documento apresenta diretrizes para o atendimento nas intuições baseadas no reconhecimento das diversidades e pluralidades das dimensões infantis.

Com a nova reforma da educação brasileira e a implantação da Base Nacional Comum Curricular, a Educação Infantil passa mais uma vez por novos (velhos) desafios. As crianças são novamente silenciadas e perdem o direito a uma educação integral para adquirirem habilidades e competências práticas, cognitivas e socioemocionais de forma fragmentada, mecânica e alienada.

Pensar a qualidade da Educação Infantil, reconhecendo a criança como um sujeito histórico, social, produtor de cultura, que tem voz e vez e é protagonista de seu aprendizado, configura-se numa luta que ocorre há muito tempo e não se findará. A falta qualidade do atendimento e a própria negligência na efetividade das legislações, desenham os impasses na composição de um currículo significativo e eficaz, que garanta às crianças o direito a uma educação de qualidade, direito a uma formação integral e o direito à própria infância.

\section{REFERÊNCIAS}

ANTUNES, R. O privilégio da servidão: o novo proletariado de serviços na era digital. 1. ed. São Paulo: Boitempo, 2018.

BARROS, F. C. O. M. Cadê o brincar? da educação infantil para o ensino fundamental. São Paulo: Cultura Acadêmica, 2009. 
BRASIL. Ministério da Educação. Secretaria de Educação Básica. Diretrizes curriculares para a Educação Infantil. Brasília, DF: MEC, SEB, 2009.

BRASIL. Presidência da República. Casa Civil. Lei n. 11.274, de 6 de fevereiro de 2006. Altera a redação dos artigos 29, 30, 32 e 87 da Lei no 9.394 de 20 de dezembro de 1996, que estabelece as diretrizes e bases da educação nacional, dispondo sobre a duração de 9 (nove) anos para o ensino fundamental, com matrícula obrigatória a partir dos 6 (seis) anos de idade. Brasília, DF, 6 fev. 2006. Disponível em: http://www.planalto.gov.br/ccivil_03/_ato20042006/2006/lei/111274.htm. Acesso em: 10 dez. 2019.

BRASIL. Ministério da Educação. Secretaria da Educação Básica. Base Nacional Comum Curricular. Brasília, DF: MEC, SEB, 2017. Disponível em:

http://basenacionalcomum.mec.gov.br/abase/\#infantil. Acesso em: 10 junho 2019.

CORSARO, W. A. Sociologia da infância. Porto Alegre: Artmed, 2011.

DANTAS, E. L. S. Educação Infantil, cultura, currículo e conhecimento: sentidos da discussão. 2016. Tese (Doutorado em Educação) - Universidade Federal do Rio Grande do Norte, Natal, 2016.

KRAMER, S. A política do pré-escolar no Brasil: a arte do disfarce. São Paulo: Cortez, 1995.

KRAMER, S. Infância, cultura contemporânea e educação contra a barbárie. Revista Teias, v. 1, n. 2, ago. 2007. ISSN 1982-0305. Disponível em: https://www.epublicacoes.uerj.br/index.php/revistateias/article/view/23857. Acesso em: 10 dez. 2019.

MARSIGLIA et al. A Base Nacional Comum Curricular: um episódio de esvaziamento da escola no Brasil. In: Marxismo e educação em debate. Salvador, 2017. n. 1, p. 107-121.

MONTEIRO, C. C.; CASTRO, L. O.; HERNECK, H. R. O silenciamento da Educação Infantil: proposta da Base Nacional Comum Curricular (BNCC). Pedagogia em ação. Revista Eletrônica do Curso de Pedagogia da Pontifícia Universidade Católica de Minas Gerais, Belo Horizonte, v. 10, n. 1, 2018.

QVORTRUP, J. Nove teses sobre a infância como fenômeno social. Pro-Posições, Campinas, v. 22, n. 1 (64), p. 199-211, jan./abr. 2011. Disponível em:

http://www.scielo.br/pdf/pp/v22n1/15.pdf. Acesso em 18 out. 2019. 


\section{Como referenciar este artigo}

SI SILVA, D. H. R.; HOLMO, G. C. O.; NOGUEIRA, I. S. C. Políticas de educação infantil: desafios a partir da criança e suas especificidades. Revista on line de Política e Gestão Educacional, Araraquara, v. 25, n. esp. 4, p. 2018-2030, dez. 2021. e-ISSN:1519-9029. DOI: https://doi.org/10.22633/rpge.v25iesp.4.15937

Submetido em: $20 / 08 / 2021$

Revisões requeridas em: 12/10/2021

Aprovado em: $15 / 11 / 2021$

Publicado em: 08/12/2021 